\title{
European Research Priorities for Intracerebral Haemorrhage
}

\author{
Thorsten Steiner $^{m}$ Jesper Petersson ${ }^{i}$ Rustam Al-Shahi Salman ${ }^{a}$ \\ Hanne Christensen ${ }^{c}$ Charlotte Cordonnier ${ }^{d}$ Laszlo Csiba $^{f}$ Sagi Harnof ${ }^{g}$ \\ Derk Krieger $^{c}$ David Mendelow ${ }^{b}$ Carlos Molina $^{\text {h }}$ Joan Montaner $^{\text {h }}$ \\ Karsten Overgaard ${ }^{c}$ Risto O. Roine ${ }^{j}$ Erich Schmutzhard' Turgut Tatlisumak $^{k}$ \\ Danilo Toni $^{\mathrm{n}}$ Christian Stapf ${ }^{\mathrm{e}}$ for the European Research Network on \\ Intracerebral Haemorrhage
}

\begin{abstract}
${ }^{a}$ Division of Clinical Neurosciences, Centre for Clinical Brain Sciences, University of Edinburgh, Edinburgh, and
${ }^{b}$ Department of Neurosurgery, Newcastle General Hospital, Newcastle upon Tyne, UK; ' Department of Neurology, Capital Region of Copenhagen, Copenhagen, Denmark; ${ }^{d}$ EA 1056, Department of Neurology, Université Lille-Nord de France, Lille, and ' Department of Neurology, APHP, Hôpital Lariboisière, Université Paris-VII Denis-Diderot, Paris, France; ${ }^{\mathrm{f}}$ Department of Neurology, University Hospital, Debrecen, Hungary; ${ }^{9}$ Vascular Neurosurgery, Sheba Medical Center, Tel Aviv, Israel; 'h Department of Neurology, Hospital Universitari Vall d’Hebrón, Barcelona, Spain; 'Department of Neurology, Malmö University Hospital, Malmö, Sweden; 'Department of Neurology, Turku University Hospital, Turku, and kDepartment of Neurology, Helsinki University Central Hospital, Helsinki, Finland; 'Neurointensive Care Unit, Department of Neurology, Medical University Hospital, Innsbruck, Austria; mDepartment of Neurology, Heidelberg University Hospital, Heidelberg, Germany; ' Department of Neurology, La Sapienza University, Rome, Italy
\end{abstract}

\section{Key Words}

Intracerebral haemorrhage $\cdot$ Oedema $\cdot$ Stroke $\cdot$ Mortality Disability · Outcome • Pathophysiology • Epidemiology • Imaging

\begin{abstract}
Over 2 million people are affected by intracerebral haemorrhage $(\mathrm{ICH})$ worldwide every year, one third of them dying within 1 month, and many survivors being left with permanent disability. Unlike most other stroke types, the incidence, morbidity and mortality of ICH have not declined over time. No standardised diagnostic workup for the detection of the various underlying causes of $\mathrm{ICH}$ currently exists, and the evidence for medical or surgical therapeutic interventions re-
\end{abstract}

mains limited. A dedicated European research programme for $\mathrm{ICH}$ is needed to identify ways to reduce the burden of $\mathrm{ICH}$-related death and disability. The European Research Network on Intracerebral Haemorrhage EURONICH is a multidisciplinary academic research collaboration that has been established to define current research priorities and to conduct large clinical studies on all aspects of $\mathrm{ICH}$.

Copyright $\odot 2011$ S. Karger AG, Basel

\section{Epidemiology of Intracerebral Haemorrhage}

Intracerebral haemorrhage (ICH) encompasses a diverse range of conditions, with different underlying causes, but similarly poor outcomes [1]. In brief, causes of

\section{KARGER}

Fax +41613061234 E-Mail karger@karger.ch www.karger.com
(ㄷ) 2011 S. Karger AG, Basel

$1015-9770 / 11 / 0325-0409 \$ 38.00 / 0$

Accessible online at:

www.karger.com/ced
Thorsten Steiner

Department of Neurology

Heidelberg University Hospital, Im Neuenheimer Feld 400

DE-69120 Heidelberg (Germany)

Tel. +496221 56 38673, E-Mail thorsten-steiner@med.uni-heidelberg.de 
ICH can be differentiated into arterial small and large vessel disease, venous disease, vascular malformation, haemostatic disorders, ICH in the context of other diseases and conditions, and spontaneous. 'Spontaneous' means that no cause has been found with the currently available diagnostic tests, though it is assumed that there is a cause (cryptogenic). Spontaneous also includes that no cause has been found so far, and there is no suspicion about a concept for a cause (idiopathic). A proposal for a detailed ICH classification by causes is currently prepared in the frame of the new ICH guidelines from the European Stroke Organisation. Spontaneous ICH, which is apparently unrelated to trauma, has incurred unchanged global burden over the past decades $[2,3]$. In contrast to the declining incidence of ischaemic stroke in high-income countries [4], the incidence of ICH has been constant [3]. Worldwide, the World Health Organisation estimates that 15.3 million strokes occur every year [5], of which 2-3 million are haemorrhagic. The cost of stroke in the European Union has been estimated at 27 billion EUR, of which 8.5 billion EUR are indirect costs [6]. The additional cost of ICH is estimated to be $30,000-45,000$ EUR/survivor every year [7].

During the last decade, spontaneous ICH accounted for approximately $10 \%$ of strokes in high-income countries and about $20 \%$ of strokes in low-/middle-income countries, with 1-month case fatalities of 25-35 and 30$48 \%$, respectively [4]. Cerebrovascular disease mortality also varies widely in Europe [8]. Unfortunately, the 1-month case fatality after ICH does not appear to have changed over the last few decades [3]. This is in contrast to the recent decline in the case fatality after subarachnoid haemorrhage $[9,10]$, which may be explained by multiple factors [11], including advances in endovascular treatment of intracranial aneurysms and intensive care after intervention $[9,12]$.

The incidence of spontaneous ICH is higher in Asians [3], and the major risk factors for ICH include male gender, increasing age, arterial hypertension, excessive alcohol consumption, smoking, diabetes mellitus, poor diet and obesity (waist-to-hip ratio) $[13,14]$. However, over the past decades, the incidence of $\mathrm{ICH}$ associated with prestroke hypertension appears to have declined, whereas ICH associated with use of antithrombotic drugs and presumed cerebral amyloid angiopathy in those aged $\geq 75$ years seems to have increased [2].

\section{Impact for Research}

As life expectancy rises, so will the burden of ICH. We need a better understanding of the roles of various risk factors for ICH in the elderly, to what extent they are causal and modifiable, and whether demographic transitions in low-income countries and low social status result in a larger proportion of deaths being due to $\mathrm{ICH}$.

We need more information on ICH epidemiology in low- and middle-income countries to compare racial, ethnic and population differences, as well as more estimates of ICH case fatality rates during different epochs in order to understand why they appear to have declined in some regions but not in others [3].

A joint prospective multinational study on the incidence, prevalence and socio-economic impact of spontaneous ICH - ideally - in all European Union countries is needed to propose more specific actions to be taken by health authorities at European and national levels.

\section{Pathophysiology of ICH and Impact of Brain Banking}

Most data on the pathophysiology of human ICH come from early macroscopic autopsy studies and describe neural damage from the hydrostatic pressure of ICH. Most instances of ICH occur when small (50- to $700-\mu \mathrm{m})$ penetrating arteries rupture with subsequent leaking of arterial blood into the brain parenchyma. The mass effect of the haematoma destroys neighbouring brain structures and compresses remote brain regions by midline shift and herniation. Rebleeding or haematoma growth and intraventricular expansion complicate the ICH in up to $70 \%$ of all patients within $24 \mathrm{~h}$ [15]. The fixed shape of the cranium limits its capacity to accommodate the volumetric ICH expansion, and haematoma volumes over $150 \mathrm{ml}$ almost inevitably lead to death.

The intact or partially intact brain tissue around the haematoma may resemble ischaemic brain, and neurons may die by similar mechanisms or may be subject to toxic effects of blood products. However, studies have been contradictory about the presence, extent and severity of any penumbra around ICH. Blood-brain barrier disruption and leakage of fluids and proteins contribute to brain oedema, which commonly increases over several days and may further damage the brain [16]. At a later stage, erythrocyte lysis and release of haemoglobin metabolites, iron and thrombin have been shown to trigger neurotoxic and apoptotic mechanisms in animals $[17,18]$. Another potential pathogenetic mechanism is activation of leucocytes at the injury site within the first few days, attributable to the widespread inflammation seen in animal models of ICH. All injuries to brain tissue also change genomic expression in the brain [19], which is a largely 
unexplored phenomenon in ICH patients. Experimental studies, mostly in rodents, have expanded our knowledge of pathophysiology, but are lacking confirmation in human studies so far. Furthermore, the two most popular rodent ICH models are not entirely comparable to human $\mathrm{ICH}$, and despite their usefulness in some aspects they cannot replace human tissue examinations [20].

\section{Impact for Research}

Development of novel treatments requires a precise understanding of the underlying pathophysiology and molecular mechanisms of ICH-related brain injury. Therefore, there is an urgent need for establishing large multicentre human ICH brain banks based on samples from within the haematoma, the vicinity of the haematoma, as well as from remote brain regions from patients who die at different time points following $\mathrm{ICH}$, in order to systematically study macroscopic, microscopic and ultrastructural changes.

Also, it is necessary to examine the roles of candidate molecules in causing ICH-related brain damage, to map cellular and molecular migration patterns, to study arterial wall microstructure, and to decipher post-ICH brain genetics and proteomics in sufficiently large samples.

Additionally, blood samples should be collected from ICH patients at various phases of the disease and stored for future research on biomarkers including genomewide association studies and candidate gene identification with micro-arrays.

\section{ICH Imaging and Diagnostic Workup}

Studies on sensitivity and specificity of prehospital clinical diagnosis of ICH are contradictory [21-28]. Therefore, brain imaging is the cornerstone for ICH diagnosis because haemorrhagic and ischaemic stroke cannot be differentiated on clinical grounds alone. Brain computed tomography (CT) detects symptomatic $\mathrm{ICH}$ within minutes of symptom onset but may lack sensitivity if the bleeding is hyperacute (uncoagulated blood) or CT brain imaging is delayed for more than 1 week after ICH onset (hematoma isodense to brain tissue) [29]. Magnetic resonance imaging (MRI) with $\mathrm{T}_{2}{ }^{*}$-weighted gradient-recalled echo sequences identifies ICH soon after onset and reliably detects chronic posthaemorrhagic iron deposits [30]. Initial imaging may also be used as part of prognostic scores predicting clinical outcome after acute ICH [31]. Hyperacute CT angiography followed by a postcontrast scan may in up to $40 \%$ identify a 'spot sign' - 1 or more hyperintense spots in the haematoma representing a contrast leak. Its presence is a recently established predictor of haematoma expansion and poor outcome [32-34]. E-learning programmes may permit easy implementation in clinical practice [35].

After the ascertainment of the haemorrhagic nature of the stroke, a swift diagnosis of the underlying cause can expedite management to improve outcome or prevent recurrent ICH. For both MRI and CT, baseline and serial studies can be used to identify patients who may benefit from acute interventions (e.g. anticoagulation for intracranial venous thrombosis or placement of an external ventricular drain for hydrocephalus). The reliable detection of an underlying arterial aneurysm, arteriovenous malformation or dural arteriovenous fistula may require additional intra-arterial digital subtraction angiography because timely treatment can prevent recurrent ICH [1].

In line with the low level of evidence of the existing international recommendations [36-38], clinical practice varies widely across Europe: In a survey of current practice, the types and timing of investigations varied considerably between specialties and countries. Generally, younger age, a lobar bleeding location and the absence of pre-existing arterial hypertension prompt further diagnostic studies beyond the initial CT imaging [39]. None of these factors, however, reliably predicts any underlying vascular pathology. MRI and angiographic imaging seem worthwhile depending on the patient's clinical condition [40], but the availability and choice of these modalities will depend on local resources, regional standards and national healthcare systems. Until further studies of the diagnostic accuracy of non-invasive investigations such as CT or magnetic resonance angiography have been performed, these techniques cannot replace intra-arterial digital subtraction angiography for the investigation of ICH [39].

\section{Impact for Research}

Given the large variety of underlying vascular pathologies, the concept of 'primary' ICH should be replaced by a more systematic stratification into specific diagnostic subtypes. Testable ICH standard diagnostic criteria need to be defined by underlying aetiology, including working criteria for diagnostic certainty according to imaging and other diagnostic tools.

The increasing sensitivity of diagnostic tests, changes in the epidemiology of ICH and discovery of newly identified risk factors ask for a new classification of ICH according to aetiological subgroups. Planned as part of the updated European Stroke Organisation guidelines on ICH diagnosis and management, a new ICH classifica- 
tion will help to standardise inclusion criteria for future observational research and controlled clinical trials.

Future research should also focus on the appropriate type and timing of diagnostic investigations after spontaneous ICH onset. This includes development of a decision tree defining standard diagnostic and management algorithms, and the most cost-effective strategies for investigating patients at older ages and in resource-poor settings.

More refined imaging tools and diagnostic signs (e.g. the spot sign on postcontrast multidetector row CT) may help to better define subgroups at risk for haematoma expansion or rebleeding $[32,41]$. Only few reports exist on the spot sign on contrast-enhanced MRI $[42,43]$ and warrant further study. This may improve patient selection for future clinical trials in acute ICH as patients with a high risk of haematoma expansion may also show the highest treatment effect $[44,45]$.

Alternative imaging tools, such as transcranial ultrasound, should be explored for early ICH diagnosis and non-invasive follow-up imaging [46]. Clinical grading scales predicting outcome after ICH could be improved by identifying the underlying cause and incorporating more specific imaging data [47].

\section{Prevention}

Currently established predictors of ICH include modifiable risk factors (arterial hypertension, diabetes mellitus, excessive alcohol consumption, smoking, poor diet, overweight, quality of anticoagulant therapy) and nonmodifiable risk factors such as male gender, increasing age, ethnic origin and certain genetic predispositions $[13$, 48]. Presence of 1 or more of these factors may lead to subsequent structural changes of the small brain vessels, including arteriolosclerosis, lipohyalinosis and eventual formation of micro-aneurysms. The various effects of many risk factors may result in so-called cerebral small vessel disease, which underlies many ICH cases. The population prevalence of cerebral small vessel disease - even without $\mathrm{ICH}$ - increases with age and may lead to progressive cognitive decline and mainly determines the burden of vascular dementia in the general population.

\section{Medical Prevention of ICH}

As for ischaemic stroke prevention, guidelines recommend that survivors of ICH should stop smoking, limit their alcohol consumption and actively treat any con- comitant risk factors mentioned above, in particular elevated blood pressure [36-38]. After the acute phase of $\mathrm{ICH}$, the large randomised PROGRESS trial found that blood pressure reduction (using the angiotensin-converting enzyme inhibitor perindopril and the diuretic indapamide) was beneficial in the prevention of future vascular events [49]. The effect was particularly strong for secondary prevention of ICH: an average systolic blood pressure reduction of $12 \mathrm{~mm} \mathrm{Hg}$ decreased the risk of recurrent ICH by up to $76 \%$ [50].

ICH prevention (primary and secondary) becomes particularly important in patients with a need for oral anticoagulation [51]. The introduction of new oral anticoagulants may decrease the risk of (re)bleeding compared to warfarin by as much as $1 / 3$ to $2 / 3$ [52-54]. However, the problem of oral anticoagulant therapy-related ICH will remain and possibly even increase in absolute numbers. There are two reasons for this: (1) the new drugs may be prescribed more liberally because of a better safety profile, and (2) the number of patients with atrial fibrillation is expected to increase substantially over the next decade [55]. Just as for warfarin-related ICH, questions like best acute treatment and restart of secondary prevention will need to be answered.

\section{Surgical Prevention of ICH}

The quality of non-invasive brain imaging tools, such as CT, MRI, as well as vascular imaging by means of CT angiography and magnetic resonance angiography, has improved constantly over the past. The increased accessibility leads to a growing number of incidentally diagnosed haemorrhage-prone vascular malformations at a stage before actual ICH or even clinical symptoms have occurred. Unruptured aneurysms, unruptured brain arteriovenous malformations and incidental cavernous malformations often represent a management dilemma because treatment decisions have to consider the risk of invasive versus non-invasive strategies. Depending on lesion type, size and location, possible interventional techniques include neurosurgery, endovascular embolisation or stereotactic radiosurgery. So far, however, no controlled clinical study has proven the clinical benefit of any of such interventions for primary haemorrhage prevention in affected patients [56].

Impact for Research

Longitudinal population-based cohort studies will have to test the preventive effect of active risk factor mod- 
ification on the incidence and recurrence rate of $\mathrm{ICH}$. The impact may be different according to subtypes of underlying small vessel disease (e.g. amyloid angiopathy, hypertension-induced arteriolosclerosis or genetic small vessel disease). Improved risk factor management may also have a favourable effect on the burden of vascular dementia in the general population. Also, there is a need for studying the double risk of stroke with small vessel disease (ischaemic and haemorrhagic stroke) in future ICH research, including adequate outcome measures in future ICH research.

For an increasing number of patients diagnosed with haemorrhage-prone but as yet unruptured vascular lesions (such as aneurysms, arteriovenous or cavernous malformations), controlled clinical ICH prevention trials are needed to compare the risk/benefit ratio of preventive lesion eradication versus non-interventional management. One international randomised clinical trial evaluating the management of unruptured brain arteriovenous malformations is currently ongoing (www.arubastudy.org) including many study sites across Europe.

\section{Acute Medical ICH Treatment}

Stroke Unit and Neurocritical Care Unit Management

The latest Cochrane Review update by the Stroke Unit Trialist's Collaboration confirmed the benefit of stroke unit care for unselected stroke patients [57]. Admission to a neurological/neurosurgical intensive care unit has been shown to be associated with a reduced mortality rate after ICH in an observational study design [58]. While there are no indications that patients with ICH have less benefit than patients with ischaemic stroke, studies were not powered to detect such differences. The European Stroke Organisation guidelines recommend standard stroke care defined as dedicated care with trained personnel, monitoring of physiological parameters and early mobilisation. There is largely only class IV evidence for any single general care item such as antibiotic treatment of respiratory infections, early mobilisation or use of a nasogastric tube. Whether patients with $\mathrm{ICH}$ respond differently to any of these measures is unclear, and early decision-making regarding 'do not resuscitate' orders may systematically bias available data sets [59].

Volume of ICH and presence of intraventricular haemorrhage were repeatedly found to be the two major predictors of death or severe disability in the acute phase after spontaneous ICH [60-62]. Volumes of ICH or intraventricular haemorrhage or both increase within $24 \mathrm{~h}$ in at least $70 \%$ of patients [15]. Therefore, treatments aimed at reduction of volume, restriction of growth and removal of ventricular haemorrhage may improve outcome. Furthermore, increasing perihaematoma oedema may add to the mass effect. However, the association between perihaematoma oedema and acute/subacute morbidity and mortality appears contradictory $[63,64]$.

Methods to predict the likelihood of ICH growth have been proposed and need verification (e.g. density and shape of the ICH on CT [65], or spot sign on CT angiography $[32,34,45])$. Haematoma expansion may also lead to increased intracranial pressure. Patients with a Glasgow Coma Scale score $\leq 8$ requiring intubation and artificial ventilation may benefit from an intraventricular or parenchymal intracranial pressure monitoring. Increased intracranial pressure is treated according to accepted general guidelines, including osmotherapy (mannitol or hypertonic saline as boluses), and intermittent cautious short-term hyperventilation (aiming at $\mathrm{pCO}_{2}$ 32-35 $\mathrm{mm} \mathrm{Hg}$ ), whereas decompressive craniectomy and moderate hypothermia might be efficacious [36, 37]. However, none of these procedures has been subject to controlled clinical trials.

\section{Haemostatic Therapy}

Non-surgical concepts to restrict growth include the use of haemostatic agents and blood pressure lowering. $\varepsilon$-Amino caproic acid (EACA), tranexamic acid (TXA) and activated recombinant factor VII (rFVIIa) were used in trials for spontaneous ICH [61, 66-68].

The 4 randomized controlled trials of haemostatic drugs for acute ICH included 423 placebo and 975 patients who received haemostatic drug, 973 on rFVIIa and 2 EACA, and thus this comparison was mainly a comparison between placebo and rFVIIa [69]. Haemostatic drug therapy did not reduce the case fatality and risk of death and dependency on modified Rankin Scale within 90 days, despite a significant reduction in haematoma growth. There was a trend towards more participants on rFVIIa experiencing thrombo-embolic serious adverse events. A post hoc analysis suggested several reasons why the largest haemostatic drug trial (FAST [61]) showed a neutral result, including a treatment time window beyond $2.5 \mathrm{~h}$, median patient age $>70$ years, average intraventricular haemorrhage volume $>5 \mathrm{ml}$, and ICH volume of more than $60 \mathrm{ml}$ [44]. This implies that a shorter time to detection (e.g. by CT) may improve the power of subsequent trials. 
EACA was evaluated in a small retrospective study, which included 5 patients within $12 \mathrm{~h}$ after an acute ICH. These patients were treated with EACA intravenously $5 \mathrm{~g}$ during the 1st hour and with $1 \mathrm{~g} / \mathrm{h}$ during the following $23 \mathrm{~h}$ [66]. Haematoma enlargement occurred in 3 of $5 \mathrm{pa}-$ tients, while it occurred in 2 of 9 patients who were not treated with EACA.

TXA works when the coagulation mechanism has been set off and exhibits its haemostatic effect by inhibiting plasminogen [70], thereby inhibiting the cascade of enzymes which dissolve a thrombus. Its use for a variety of other indications suggests that it may be effective in reducing $\mathrm{ICH}$ growth. A protocol of rapid infusion of TXA ( $2 \mathrm{~g}$ over $10 \mathrm{~min})$ and blood pressure restriction (systolic blood pressure below $150 \mathrm{~mm} \mathrm{Hg}$ ) was used in 223 consecutive and retrospectively analysed patients within $24 \mathrm{~h}$ after spontaneous ICH [67]. Haematoma enlargement (defined as $\geq 20 \%$ volume increase) was observed in $8(4.3 \%)$ of 188 patients. The CRASH-2 trial included trauma patients and compared the risk of death due to bleeding in 10,096 patients who were treated with TXA and 10,115 who received placebo. Death due to bleeding was significantly reduced from $574(5.7 \%)$ in the placebo group to 489 (4.9\%) in the TXA group for all causes of trauma [71]. No significant difference was found in the subgroup of patients with traumatic brain injury, though the trial was not powered for this analysis. A Cochrane review of the randomised trials with TXA in patients undergoing elective surgery identified 53 studies including 3,836 participants [72], and TXA reduced the need for blood transfusion by one third. TXA has been shown to decrease early rebleeding after aneurysmal subarachnoid haemorrhage from $10.8 \%$ among controls to $2.4 \%$, while reducing mortality from 16.3 to $12.9 \%$; however, the doses and treatment durations differ from those used for ICH so far [73]. Whether the occurrence of thrombo-embolic complications is different, e.g. compared with rFVIIa treatment, is not known.

\section{Blood Pressure Control}

Mechanistically it seems plausible that elevated blood pressure is a driving force for haematoma enlargement. On the other hand, lowering blood pressure too much may lead to ischaemia. However, several recent publications suggest the latter being less important $[74,75]$. After positron emission tomography studies had found no evidence of hypoperfusion or increased oxygen extraction in the brain tissue surrounding the $\mathrm{ICH}$, it was assumed that antihypertensive treatment would not harm the perihaematomal tissue [76]. Intensive lowering of blood pressure was applied in the 'intensive blood pressure reduction in acute cerebral haemorrhage trial' (INTERACT) [77]. Overall, 400 patients were randomised to either intensive (systolic blood pressure $\leq 140 \mathrm{~mm} \mathrm{Hg}$ within $1 \mathrm{~h}$ ) or guideline-based blood pressure treatment (systolic blood pressure $\leq 180 \mathrm{~mm} \mathrm{Hg}$ ). Intensive blood pressure restriction for 7 days turned out to be feasible, safe and to reduce haematoma growth on 24-hour follow-up imaging. The Antihypertensive Treatment of Acute Cerebral Haemorrhage (ATACH) trial looked at three different blood pressure target groups in an escalating design - blood pressure was kept within 3 different ranges for 18-24 h: group 1 $(\mathrm{n}=18)$ 170-200 mm Hg, group $2(\mathrm{n}=20) 140-170 \mathrm{~mm}$ $\mathrm{Hg}$ and group $3(\mathrm{n}=22) \quad 110-140 \mathrm{~mm} \mathrm{Hg}$ [78]. The observed proportions of neurological deterioration and serious adverse events were below the prespecified safety thresholds, and the 3-month mortality rate was lower than expected in all systolic blood pressure tiers.

\section{Impact for Research}

The application of haemostatic drugs in spontaneous ICH seems to reduce haematoma growth, despite the fact that different definitions of growth or haematoma enlargement were used [79]. Still there is no study that has shown that reduction of haematoma enlargement has a beneficial clinical effect. By far, most information has come from trials on rFVIIa, but other drugs, e.g. TXA, might turn out to be effective. The INTERACT 2 phase III trial is ongoing to establish the efficacy and safety of aggressive blood pressure lowering compared to guideline-based blood pressure targets on death and dependency at 3 months; the trial includes many sites in Europe [80]. The interaction between haemostatic and antihypertensive approaches to treatment will need to be established as part of subsequent haemostatic drug trials.

ICH and ischemic stroke trials have some aspects in common, for example outcome predictors such as time window, lesion volume and clinical status on admission, or outcome measures like modified Rankin Score, National Institutes of Health Stroke Scale, Glasgow Outcome Score or Barthel index. Yet, important differences should be considered in ICH research, particularly outcome predictors like intraventricular volume, haematoma expansion predictors like spot sign and outcome measures like socio-economic impact and the association between risk factors and pathology (e.g. hypertension and location). Another factor that needs to be studied further is the impact of do-not-resuscitate orders on outcome in $\mathrm{ICH}$. 


\section{Acute Surgical ICH treatment}

About $10 \%$ of spontaneous ICH are located in the brainstem or cerebellum [81]. Current guidelines recommend evacuation of cerebellar ICH when its diameter exceeds $2-3 \mathrm{~cm}$, if symptomatic hydrocephalus is present or if brainstem compression arises [37, 38]. The application of an external ventricular drain is recommended in case of hydrocephalus and signs of clinical deterioration. None of these recommendations are based on prospective clinical trials with clearly defined selection criteria. The same holds true for the management of external ventricular drains during the course of the disease $[82,83]$.

While there is little doubt that the removal of an expanding posterior fossa haematoma improves acute ICH outcome, controversy exists about surgical interventions for spontaneous supratentorial ICH. Data collected from non-randomised studies have usually shown that the outcome has been worse in the surgically treated group. This is because the most severely affected patients have been subjected to surgery while the less severe cases have been treated conservatively [84].

The STICH trial was the largest prospective randomised controlled trial of early surgery compared with initial conservative treatment [85]. In this study, 1,033 patients were randomised within $72 \mathrm{~h}$ to initial conservative treatment or early surgery. The result was neutral for death and disability at 3 months, but a subgroup analysis suggested that superficial lobar haematomas treated with craniotomy were more likely to benefit from early surgical intervention.

A meta-analysis of the 13 prospective randomised controlled trials of surgery versus conservative treatment has demonstrated a significant reduction in mortality and a strong indication of reduced morbidity as well [86, 87]. A 14th trial has recently been published also suggesting that (minimally invasive) surgical intervention is of value [88]. One problem of small trials that looked at surgery within $4 \mathrm{~h}$ though was an increased rate of rebleeding [89].

\section{Impact for Research}

Both ICH and intraventricular haematoma volumes play a key role in the management of $\mathrm{ICH}$. As in other stroke types, the timing between $\mathrm{ICH}$ onset and treatment initiation in any surgical ICH trial may be crucial, since most of the volume expansion occurs within the first $24 \mathrm{~h}$.

The role of surgery within this time frame is as yet unclear, but the issue is subject to several currently ongoing clinical trials: one prospective randomised controlled tri- al has been initiated (STICH II) to test the effect of surgery in patients with superficial lobar haematomas without ventricular haemorrhage or hydrocephalus. A target of 600 patients should be achieved by the autumn of 2011; many European sites are currently involved.

Another trial of minimal intervention surgery (MISTIE) is evaluating the role of intracavity tissue plasminogen activator with catheter drainage also for supratentorial spontaneous haematomas. A third ongoing prospective randomised controlled trial (CLEAR III) is randomising patients with ventricular haemorrhage to intraventricular recombinant tissue plasminogen activator administration compared to placebo and catheter drainage. Efficacy of this approach has been shown so far only in small prospective trials $[90,91]$.

Clinical trials with clearly defined selection criteria on surgical management of cerebellar ICH and hydrocephalus are needed. Also, the question when to place, change or replace an external ventricular drain in patients with ICH-related hyrocephalus needs to be answered in controlled clinical trials.

\section{Conclusion and Perspectives}

Spontaneous ICH does affect a significant proportion of the European and worldwide population. The mortality is significantly higher than in ischaemic stroke, and the prognosis is still poor, creating a large socio-economic burden. However, very few management strategies are supported by good evidence, and specific research priorities for ICH have been lacking so far in Europe [92]. On the other hand, promising results from studies on pathophysiological mechanisms and from clinical trials, as well as combined efforts from different research focuses in the area, provide optimism for the future.

As response to a lacking European research agenda for $\mathrm{ICH}$, a dedicated academic initiative has now been established to constitute a multicentre European Network for $\mathrm{ICH}$ research (called EURONICH, see the appendix). The network focuses on setting research priorities, planning and executing high-impact large clinical studies, including controlled clinical trials, the collection of blood samples for DNA and biomarker studies, a brain imaging archive, and a brain tissue bank for deciphering molecular and cellular mechanisms of ICH and its underlying disease entities. Multidisciplinary diagnostic and therapeutic strategies should be optimised sharing the expertise of vascular neurology, diagnostic and interventional neuroradiology, neurosurgery, anaesthesiology, neuropsychol- 
ogy and rehabilitation, to name but a few. The ultimate aim is to improve patient care across all member states of the European Union, and beyond. Interested colleagues and neurovascular teams in Europe are welcome to join the effort (http://www.euronich.de).

\section{Appendix}

EURONICH is an initiative of researchers and their coworkers in the field of ICH from 14 European countries (http://www. euronich.de). It is an open network that welcomes other clinical and basic science researchers to participate in this multidisciplinary collaboration. Finances used to make the EURONICH initiative come to life come from money that is supplied by institutional research support, as well as from research grants and ongoing clinical studies in the area of ICH.

Members of EURONICH have performed several planning meetings on research projects and scientific sessions during the European Stroke Conferences in 2009 (Stockholm, Sweden), 2010 (Barcelona, Spain) and 2011 (Hamburg, Germany).

Currently funded ICH-related studies within the EURONICH network include: (1) ARUBA - A randomised trial of unruptured brain arteriovenous malformations; sponsor: NIH/NINDS (USA); (2) INCH - international normalised ratio normalisation in patients with coumadin-related ICH; sponsor: Heidelberg University Hospital (Germany); (3) INTERACT2 - Second Intensive Blood Pressure Reduction in Acute Cerebral Haemorrhage Trial; sponsor: National Health and Medical Research Council (Australia).

\section{Disclosure Statement}

Hanne Christensen has received research funds from the Capital Region of Denmark and Medtronic Inc., and speaker and advisory honoraria from Boehringer-Ingelheim Danmark A/S, Medtronic Inc. and Allergan A/S.

Christian Stapf has received research funds through grants from the NIH/NINDS (USA), the Australian National Health and Medical Research Council and the French Ministry of Health.

Erich Schmutzhard has received research funds from Actelion and Bayer Austria, and speaker honoraria from Actelion, Novo Nordisk and Baxter.

Thorsten Steiner has received research funds from Octapharma, and speaker honoraria from Novo Nordisk and Octapharma.

\section{References}

1 Al-Shahi Salman R, Labovitz DL, Stapf C: Spontaneous intracerebral haemorrhage. BMJ 2009;339:b2586.

-2 Lovelock CE, Molyneux AJ, Rothwell PM: Change in incidence and aetiology of intracerebral haemorrhage in Oxfordshire, UK, between 1981 and 2006: a population-based study. Lancet Neurol 2007;6:487-493.

- 3 Van Asch CJ, Luitse MJ, Rinkel GJ, van der Tweel I, Algra A, Klijn CJ: Incidence, case fatality, and functional outcome of intracerebral haemorrhage over time, according to age, sex, and ethnic origin: a systematic review and meta-analysis. Lancet Neurol 2010; 9:167-176.

4 Feigin VL, Lawes CM, Bennett DA, BarkerCollo SL, Parag V: Worldwide stroke incidence and early case fatality reported in 56 population-based studies: aA systematic review. Lancet Neurol 2009;8:355-369.

5 World Health Organisation: Global burden of disease. Geneva, WHO, 2010.

6 Di Carlo A: Human and economic burden of stroke. Age Ageing 2009;38:4-5.

7 Weimar C, Weber C, Wagner M, Busse O, Haberl RL, Lauterbach KW, Diener HC: Management patterns and health care use after intracerebral hemorrhage: a cost-of-illness study from a societal perspective in Germany. Cerebrovasc Dis 2003;15:29-36.
8 Muller-Nordhorn J, Binting S, Roll S, Willich $\mathrm{SN}$ : An update on regional variation in cardiovascular mortality within Europe. Eur Heart J 2008;29:1316-1326.

-9 Lovelock CE, Rinkel GJ, Rothwell PM: Time trends in outcome of subarachnoid hemorrhage: population-based study and systematic review. Neurology 2010;74:1494-1501.

10 Nieuwkamp DJ, Setz LE, Algra A, Linn FH, de Rooij NK, Rinkel GJ: Changes in case fatality of aneurysmal subarachnoid haemorrhage over time, according to age, sex, and region: a meta-analysis. Lancet Neurol 2009; 8:635-642.

11 Al-Shahi Salman R, Sudlow CL: Case fatality after subarachnoid haemorrhage: declining, but why? Lancet Neurol 2009;8:598-599.

12 Van der Schaaf I, Algra A, Wermer M, Molyneux A, Clarke M, van Gijn J, Rinkel G: Endovascular coiling versus neurosurgical clipping for patients with aneurysmal subarachnoid haemorrhage. Cochrane Database Syst Rev 2005;4:CD003085.

13 O’Donnell MJ, Xavier D, Liu L, Zhang H, Chin SL, Rao-Melacini P, Rangarajan S, Islam S, Pais P, McQueen MJ, Mondo C, Damasceno A, Lopez-Jaramillo P, Hankey GJ, Dans AL, Yusoff K, Truelsen T, Diener HC, Sacco RL, Ryglewicz D, Czlonkowska A, Weimar C, Wang X, Yusuf S: Risk factors for ischaemic and intracerebral haemorrhagic stroke in 22 countries (the Interstroke Study): a case-control study. Lancet 2010; 376:112-123. $\checkmark 14$ Ariesen MJ, Claus SP, Rinkel GJ, Algra A: Risk factors for intracerebral hemorrhage in the general population: a systematic review. Stroke 2003;34:2060-2065.

15 Davis SM, Broderick J, Hennerici M, Brun NC, Diringer MN, Mayer SA, Begtrup K, Steiner T: Hematoma growth is a determinant of mortality and poor outcome after intracerebral hemorrhage. Neurology 2006;66: 1175-1181.

16 Sansing LH, Kaznatcheeva EA, Perkins CJ, Komaroff E, Gutman FB, Newman GC: Edema after intracerebral hemorrhage: correlations with coagulation parameters and treatment. J Neurosurg 2003;98:985-992.

17 Xi G: Intracerebral hemorrhage: pathophysiology and therapy. Neurocrit Care 2004;1: 5-18.

18 Gong C, Boulis N, Qian J, Turner DE, Hoff JT, Keep RF: Intracerebral hemorrhage-induced neuronal death. Neurosurgery 2001; 48:875-882.

19 Lu A, Tang Y, Ran R, Ardizzone TL, Wagner KR, Sharp FR: Brain genomics of intracerebral hemorrhage. J Cereb Blood Flow Metab 2006;26:230-252

20 Strbian D, Durukan A, Tatlisumak T: Rodent models of hemorrhagic stroke. Curr Pharm Des 2008; 14:352-358.

21 Weir CJ, Murray GD, Adams FG, Muir KW, Grosset DG, Lees KR: Poor accuracy of stroke scoring systems for differential clinical diagnosis of intracranial haemorrhage and infarction. Lancet 1994;344:999-1002. 
-22 Badam P, Solao V, Pai M, Kalantri SP: Poor accuracy of the Siriraj and Guy's Hospital stroke scores in distinguishing haemorrhagic from ischaemic stroke in a rural, tertiary care hospital. Natl Med J India 2003; 16 : 8-12.

23 Soman A, Joshi SR, Tarvade S, Jayaram S: Greek stroke score, Siriraj score and Allen score in clinical diagnosis of intracerebral hemorrhage and infarct: validation and comparison study. Indian J Med Sci 2004;58: 417-422.

24 Godoy DA, Pinero G, Di Napoli M: Predicting mortality in spontaneous intracerebral hemorrhage: can modification to original score improve the prediction? Stroke 2006; 37:1038-1044.

-25 Kolapo KO, Ogun SA, Danesi MA, Osalusi BS, Odusote KA: Validation study of the Siriraj stroke score in African Nigerians and evaluation of the discriminant values of its parameters: a preliminary prospective CT scan study. Stroke 2006;37:1997-2000.

-26 Ozeren A, Bicakci S, Burgut R, Sarica Y, Bozdemir H: Accuracy of bedside diagnosis versus Allen and Siriraj stroke scores in Turkish patients. Eur J Neurol 2006;13:611-615.

27 Connor MD, Modi G, Warlow CP: Accuracy of the Siriraj and Guy's Hospital stroke scores in urban South Africans. Stroke 2007; 38:62-68.

28 Valiente RA, de Miranda-Alves MA, Silva GS, Gomes DL, Brucki SM, Rocha MS, Massaro AR: Clinical features associated with early hospital arrival after acute intracerebral hemorrhage: challenges for new trials. Cerebrovasc Dis 2008;26:404-408.

-29 Lovelock CE, Anslow P, Molyneux AJ, Byrne JV, Kuker W, Pretorius PM, Coull A, Rothwell PM: Substantial observer variability in the differentiation between primary intracerebral hemorrhage and hemorrhagic transformation of infarction on CT brain imaging. Stroke 2009;40:3763-3767.

-30 Kidwell CS, Wintermark M: Imaging of intracranial haemorrhage. Lancet Neurol 2008;7:256-267.

- 31 Hemphill JC 3rd, Bonovich DC, Besmertis L, Manley GT, Johnston SC: The ICH score: a simple, reliable grading scale for intracerebral hemorrhage. Stroke 2001;32:891-897.

- 32 Wada R, Aviv RI, Fox AJ, Sahlas DJ, Gladstone DJ, Tomlinson G, Symons SP: CT angiography 'spot sign' predicts hematoma expansion in acute intracerebral hemorrhage. Stroke 2007;38:1257-1262.

- 33 Ederies A, Demchuk A, Chia T, Gladstone DJ, Dowlatshahi D, Bendavit G, Wong K, Symons SP, Aviv RI: Postcontrast CT extravasation is associated with hematoma expansion in CTA spot negative patients. Stroke 2009;40:1672-1676.

- 34 Hallevi H, Abraham AT, Barreto AD, Grotta JC, Savitz SI: The spot sign in intracerebral hemorrhage: the importance of looking for contrast extravasation. Cerebrovasc Dis 2010;29:217-220.
35 Havsteen I, Christensen A, Nielsen JK, Christensen L, Krieger DW, Christensen $\mathrm{H}$ : E-learn computed tomographic angiography: a proposed educational tool for computed tomographic angiography in acute stroke. J Stroke Cerebrovasc Dis 2011, E-pub ahead of print.

36 Broderick J, Connolly S, Feldmann E, Hanley D, Kase C, Krieger D, Mayberg M, Morgenstern L, Ogilvy CS, Vespa P, Zuccarello M: Guidelines for the management of spontaneous intracerebral hemorrhage in adults - 2007 update: a guideline from the American Heart Association/American Stroke Association Stroke Council, High Blood Pressure Research Council, and the Quality of Care and Outcomes in Research Interdisciplinary Working Group. Stroke 2007;38: 2001-2023.

- 37 Steiner T, Kaste M, Forsting M, Mendelow D, Kwiecinski H, Szikora I, Juvela S, Marchel A, Chapot R, Cognard C, Unterberg A, Hacke $\mathrm{W}$ : Recommendations for the management of intracranial haemorrhage. 1. Spontaneous intracerebral haemorrhage. The European Stroke Initiative writing committee and the writing committee for the EUSI executive committee. Cerebrovasc Dis 2006;22:294316.

38 Morgenstern LB, Hemphill JC 3rd, Anderson C, Becker K, Broderick JP, Connolly ES Jr, Greenberg SM, Huang JN, Macdonald RL, Messe SR, Mitchell PH, Selim M, Tamargo RJ: Guidelines for the management of spontaneous intracerebral hemorrhage: a guideline for healthcare professionals from the American Heart Association/American Stroke Association. Stroke 2010;41:21082129.

-39 Cordonnier C, Klijn CJ, van Beijnum J, AlShahi Salman R: Radiological investigation of spontaneous intracerebral hemorrhage: systematic review and trinational survey. Stroke 2010;41:685-690.

40 Fiebach JB, Schellinger PD, Gass A, Kucinski T, Siebler M, Villringer A, Olkers P, Hirsch JG, Heiland S, Wilde, Jansen O, Rother J, Hacke W, Sartor K: Stroke magnetic resonance imaging is accurate in hyperacute intracerebral hemorrhage: a multicenter study on the validity of stroke imaging. Stroke 2004;35:502-506.

41 Goldstein JN, Fazen LE, Snider R, Schwab K, Greenberg SM, Smith EE, Lev MH, Rosand $\mathrm{J}$ : Contrast extravasation on CT angiography predicts hematoma expansion in intracerebral hemorrhage. Neurology 2007;68:889894.

42 Murai Y, Ikeda Y, Teramoto A, Tsuji Y: Magnetic resonance imaging-documented extravasation as an indicator of acute hypertensive intracerebral hemorrhage. J Neurosurg 1998;88:650-655.

43 Nguyen TN, Rordorf G, Schwamm LH, Smith EE: MRI contrast extravasation with enlarging hyperacute thrombolysis-related hemorrhage. Neurology 2006;66:E30.
44 Mayer SA, Davis SM, Skolnick BE, Brun NC, Begtrup K, Broderick JP, Diringer MN, Steiner T: Can a subset of intracerebral hemorrhage patients benefit from hemostatic therapy with recombinant activated factor VII? Stroke 2009;3:833-840.

$\checkmark 45$ Almandoz JE, Yoo AJ, Stone MJ, Schaefer PW, Oleinik A, Brouwers HB, Goldstein JN, Rosand J, Lev MH, Gonzalez RG, Romero JM: The spot sign score in primary intracerebral hemorrhage identifies patients at highest risk of in-hospital mortality and poor outcome among survivors. Stroke 2010;41:54-60.

-46 Perez ES, Delgado-Mederos R, Rubiera M, Delgado P, Ribo M, Maisterra O, Ortega G, Alvarez-Sabin J, Molina CA: Transcranial duplex sonography for monitoring hyperacute intracerebral hemorrhage. Stroke 2009;40:987-990.

47 Hwang BY, Appelboom G, Kellner CP, Carpenter AM, Kellner MA, Gigante PR, Sander Connolly E: Clinical grading scales in intracerebral hemorrhage. Neurocrit Care 2010; 13:141-151.

-48 Wallentin L, Yusuf S, Ezekowitz MD, Alings M, Flather M, Franzosi MG, Pais P, Dans A, Eikelboom J, Oldgren J, Pogue J, Reilly PA, Yang S, Connolly SJ: Efficacy and safety of dabigatran compared with warfarin at different levels of international normalised ratio control for stroke prevention in atrial fibrillation: an analysis of the RE-LY trial. Lancet 2010;376:975-983.

49 PROGRESS Collaborative Group: Randomised trial of a perindopril-based bloodpressure-lowering regimen among 6,105 individuals with previous stroke or transient ischaemic attack. Lancet 2001;358:1033-1041.

50 Chapman N, Huxley R, Anderson C, Bousser MG, Chalmers J, Colman S, Davis S, Donnan G, MacMahon S, Neal B, Warlow C, Woodward M: Effects of a perindopril-based blood pressure-lowering regimen on the risk of recurrent stroke according to stroke subtype and medical history: the Progress trial. Stroke 2004;35:116-121

51 Steiner T, Diringer M, Rosand J: Intracerebral hemorrhage associated with oral anticoagulant therapy: current practices and open questions. Stroke 2006;37:256-262.

52 Connolly SI, Ezekowitz MD, Yusuf S, Eikelboom J, Oldgren J, Parekh A, Pogue J, Reilly PA, Themeles E, Varrone J, Wang S, Alings M, Xavier D, Zhu J, Diaz R, Lewis BS, Darius H, Diener HC, Joyner CD, Wallentin L: Dabigatran versus warfarin in patients with atrial fibrillation. N Engl J Med 2009;361: 1139-1151.

53 The Executive Steering Committee on behalf of the Rocket AF Study Investigators: Rivaroxaban-once daily, oral, direct factor Xa inhibition compared with vitamin $\mathrm{K}$ antagonism for prevention of stroke and embolism trial in atrial fibrillation: rationale and design of the Rocket AF study. Am Heart J 2010;159:340-347 e341. 
-54 Connolly SJ, Eikelboom J, Joyner C, Diener HC, Hart R, Golitsyn S, Flaker G, Avezum A, Hohnloser SH, Diaz R, Talajic M, Zhu J, Pais P, Budaj A, Parkhomenko A, Jansky P, Commerford P, Tan RS, Sim KH, Lewis BS, Van Mieghem W, Lip GY, Kim JH, Lanas-Zanetti F, Gonzalez-Hermosillo A, Dans AL, Munawar M, O’Donnell M, Lawrence J, Lewis G, Afzal R, Yusuf S: Apixaban in patients with atrial fibrillation. N Engl J Med 2011;364: 806-817.

55 Go AS, Hylek EM, Phillips KA, Chang Y, Henault LE, Selby JV, Singer DE: Prevalence of diagnosed atrial fibrillation in adults: national implications for rhythm management and stroke prevention: the Anticoagulation and Risk Factors in Atrial Fibrillation (Atria) study. JAMA 2001;285:2370-2375.

-56 Stapf C: Endovascular management of unruptured intracranial aneurysms: the dawn of a multidisciplinary treatment paradigm. J Neurol Neurosurg Psychiatry 2006;77:e1.

57 Stroke Unit Trialists' Collaboration: Organised inpatient (stroke unit) care for stroke. Cochrane Database Syst Rev 2007; 4:CD000197.

-58 Diringer MN, Edwards DF: Admission to a neurologic/neurosurgical intensive care unit is associated with reduced mortality rate after intracerebral hemorrhage. Crit Care Med 2001;29:635-640.

- 59 Zahuranec DB, Morgenstern LB, Sanchez BN, Resnicow K, White DB, Hemphill JC 3rd: Do-not-resuscitate orders and predictive models after intracerebral hemorrhage. Neurology 2010;75:626-633.

-60 Brott T, Broderick J, Kothari R, Barsan W, Tomsick T, Sauerbeck L, Spilker J, Duldner J, Khoury J: Early hemorrhage growth in patients with intracerebral hemorrhage. Stroke 1997;28:1-5.

61 Mayer S, Brun N, Broderick J, Davis S, Diringer $\mathrm{M}$, Skolnick B, Steiner T, for the FAST Trial Investigators: Efficacy and safety of recombinant activated factor VII for acute intracerebral hemorrhage. N Engl J Med 2008; 358:2127-2137.

- 62 Steiner T, Schneider D, Mayer S, Begtrup K, Broderick J, Diringer M, Skolnick B, Davis S: Dynamics of intraventricular hemorrhage in patients with spontaneous intracerebral hemorrhage: risk factors, clinical impact, and effect of hemostatic therapy with recombinant activated factor VII. Neurosurgery 2006;59:767-774.

-63 Gebel JM Jr, Jauch EC, Brott TG, Khoury J, Sauerbeck L, Salisbury S, Spilker J, Tomsick TA, Duldner J, Broderick JP: Natural history of perihematomal edema in patients with hyperacute spontaneous intracerebral hemorrhage. Stroke 2002;33:2631-2635.
64 Arima H, Wang JG, Huang Y, Heeley E, Skulina C, Parsons MW, Peng B, Li Q, Su S, Tao QL, Li YC, Jiang JD, Tai LW, Zhang JL, Xu E, Cheng Y, Morgenstern LB, Chalmers J, Anderson CS: Significance of perihematomal edema in acute intracerebral hemorrhage: the Interact trial. Neurology 2009;73:19631968.

65 Barras C, Christensen S, MacGregor L, Tress B, Collins M, Skolnick BE, Davis S, Broderick J, Diringer M, Steiner T, Davis S: Density and shape as CT predictors of intracerebral hemorrhage growth. Stroke 2009;40: 1325-1331.

66 Piriyawat P, Morgenstern LB, Yawn D, Hall CE, Grotta JC: Treatment of acute intracerebral hemorrhage with $\varepsilon$-aminocaproic acid - a pilot study. Neurocrit Care 2004;1:47-51.

67 Sorimachi T, Fujii Y, Morita K, Tanaka R: Predictors of hematoma enlargement in patients with intracerebral hemorrhage treated with rapid administration of antifibrinolytic agents and strict blood pressure control. J Neurosurg 2007;106:250-254.

68 Mayer S, Brun N, Broderick J, Davis S, Diringer M, Skolnick B, Steiner T, for the Europe/Australasia Novo Seven ICH Trial Investigators: Recombinant activated factor VII for acute intracerebral hemorrhage. N Engl J Med 2005;352:777-785.

69 Al-Shahi Salman R: Haemostatic drug therapies for acute spontaneous intracerebral haemorrhage. Cochrane Database Syst Rev 2009;4:CD005951.

70 Lethagen S, Bjorlin G: Effect of tranexamic acid on platelet function in normal volunteers. Eur J Haematol 1991;47:77-78.

71 Shakur H, Roberts I, Bautista R, Caballero J, Coats T, Dewan Y, El-Sayed H, Gogichaishvili T, Gupta S, Herrera J, Hunt B, Iribhogbe P, Izurieta M, Khamis H, Komolafe E, Marrero MA, Mejia-Mantilla J, Miranda J, Morales C, Olaomi O, Olldashi F, Perel P, Peto R, Ramana PV, Ravi RR, Yutthakasemsunt S, for CRASH-2 trial collaborators: Effects of tranexamic acid on death, vascular occlusive events, and blood transfusion in trauma patients with significant haemorrhage (CRASH-2): a randomised, placebo-controlled trial. Lancet 2010;376:23-32.

72 Henry DA, Carless PA, Moxey AJ, O’Connell D, Stokes BJ, McClelland B, Laupacis A, Fergusson D: Anti-fibrinolytic use for minimising perioperative allogeneic blood transfusion. Cochrane Database Syst Rev 2007; 4:CD001886.

73 Hillman J, Fridriksson S, Nilsson O, Yu Z, Saveland H, Jakobsson KE: Immediate administration of tranexamic acid and reduced incidence of early rebleeding after aneurysmal subarachnoid hemorrhage: a prospective randomized study. J Neurosurg 2002;97: 771-778.
74 Powers WJ, Zazulia AR, Videen TO, Adams RE, Yundt KD, Aiyagari V, Grubb RL Jr, Diringer MN: Autoregulation of cerebral blood flow surrounding acute ( 6 to $22 \mathrm{~h}$ ) intracerebral hemorrhage. Neurology 2001; 57:18-24.

75 Schellinger PD, Fiebach JB, Hoffmann K, Becker K, Orakcioglu B, Kollmar R, Juttler E, Schramm P, Schwab S, Sartor K, Hacke W: Stroke MRI in intracerebral hemorrhage: is there a perihemorrhagic penumbra? Stroke 2003;34:1674-1679.

-76 Zazulia AR, Diringer MN, Videen TO, Adams RE, Yundt K, Aiyagari V, Grubb RL Jr, Powers WJ: Hypoperfusion without ischemia surrounding acute intracerebral hemorrhage. J Cereb Blood Flow Metab 2001;21: 804-810.

77 Anderson CS, Huang Y, Wang JG, Arima H, Neal B, Peng B, Heeley E, Skulina C, Parsons MW, Kim JS, Tao QL, Li YC, Jiang JD, Tai LW, Zhang JL, Xu E, Cheng Y, Heritier S, Morgenstern LB, Chalmers J: Intensive blood pressure reduction in acute cerebral haemorrhage trial (Interact): a randomised pilot trial. Lancet Neurol 2008;7:391-399.

78 Qureshi AI, ATACH investigators: Antihypertensive treatment of acute cerebral hemorrhage. Crit Care Med 2010;38:637-648.

79 Steiner T, Bösel J: Options to restrict hematoma expansion after spontaneous intracerebral hemorrhage. Stroke 2010;41:402-409.

$>80$ Delcourt C, Huang Y, Wang J, Heeley E, Lindley R, Stapf C, Tzourio C, Arima H, Parsons M, Sun J, Neal B, Chalmers J, Anderson C: The second (main) phase of an open, randomised, multicentre study to investigate the effectiveness of an intensive blood pressure reduction in acute cerebral haemorrhage trial (Interact2). Int J Stroke 2010;5: 110-116.

81 Sacco S, Marini C, Toni D, Olivieri L, Carolei A: Incidence and 10-year survival of intracerebral hemorrhage in a population-based registry. Stroke 2009;40:394-399.

- 82 Staykov D, Huttner HB, Struffert T, Ganslandt O, Doerfler A, Schwab S, Bardutzky J: Intraventricular fibrinolysis and lumbar drainage for ventricular hemorrhage. Stroke 2009;40:3275-3280.

83 Huttner HB, Nagel S, Tognoni E, Kohrmann M, Juttler E, Orakcioglu B, Schellinger PD, Schwab S, Bardutzky J: Intracerebral hemorrhage with severe ventricular involvement: lumbar drainage for communicating hydrocephalus. Stroke 2007;38:183-187.

84 Fernandes HM, Gregson B, Siddique S, Mendelow AD: Surgery in intracerebral hemorrhage: the uncertainty continues. Stroke 2000;31:2511-2516 
85 Mendelow AD, Gregson BA, Fernandes HM, Murray GD, Teasdale GM, Hope DT, Karimi A, Shaw MD, Barer DH: Early surgery versus initial conservative treatment in patients with spontaneous supratentorial intracerebral haematomas in the international surgical trial in intracerebral haemorrhage (Stich): a randomised trial. Lancet 2005; 9457:387-397.

86 Prasad K, Mendelow AD, Gregson B: Surgery for primary supratentorial intracerebral haemorrhage. Cochrane Database Syst Rev 2008;4:CD000200.

87 Qureshi AI, Mendelow AD, Hanley DF: Intracerebral haemorrhage. Lancet 2009;373: 1632-1644.
88 Wang WZ, Jiang B, Liu HM, Li D, Lu CZ, Zhao YD, Sander JW: Minimally invasive craniopuncture therapy vs conservative treatment for spontaneous intracerebral hemorrhage: results from a randomized clinical trial in China. Int J Stroke 2009;4: 11-16.

89 Morgenstern LB, Demchuk AM, Kim DH, Frankowski RF, Grotta JC: Rebleeding leads to poor outcome in ultra-early craniotomy for intracerebral hemorrhage. Neurology 2001;56:1294-1299.

$\checkmark 90$ Naff NJ, Carhuapoma JR, Williams MA, Bhardwaj A, Ulatowski JA, Bederson J, Bullock R, Schmutzhard E, Pfausler B, Keyl PM, Tuhrim S, Hanley DF: Treatment of intraventricular hemorrhage with urokinase: effects on 30-day survival. Stroke 2000;31 841-847.
91 Naff NJ, Hanley DF, Keyl PM, Tuhrim S, Kraut M, Bederson J, Bullock R, Mayer SA, Schmutzhard E: Intraventricular thrombolysis speeds blood clot resolution: results of a pilot, prospective, randomized, doubleblind, controlled trial. Neurosurgery 2004; 54:577-583.

92 Stapf C, van der Worp HB, Steiner T, Rinkel GJE, Nedeltchev K, Mast H, Dichgans M, Codonnier C, Chamorro A, Arnold A, AlShahi M: Stroke research priorities for the next decade - a supplement statement on intracranial haemorrhage. Cerebrovasc Dis 2007;23:318-319. 